\title{
Türkiye'deki Jeotermal Enerjinin Birincil Enerji Arzı Yönünden Değerlendirilmesi
}

\author{
Melis Alpaslan Takan ${ }^{1 *}$, Süheyla Yerel Kandemir² \\ ${ }^{1 *}$ Bilecik Şeyh Edebali Üniversitesi, Mühendislik Fakültesi, Endüstri Mühendisliği Bölümü, Bilecik, Türkiye (ORCID: 0000-0002-1458-8162) \\ ${ }^{2}$ Bilecik Şeyh Edebali Üniversitesi, Mühendislik Fakültesi, Endüstri Mühendisliği Bölümü, Bilecik, Türkiye (ORCID: 0000-0003-4056-5383) \\ (International Symposium on Multidisciplinary Studies and Innovative Technologies (ISMSIT) 2020 - 22-24 Ekim 2020)
}

(DOI: 10.31590/ejosat.824954)

ATIF/REFERENCE: Alpaslan Takan, M. \& Yerel Kandemir, S. (2020). Türkiye'deki Jeotermal Enerjinin Birincil Enerji Arzı Yönünden Değerlendirilmesi. Avrupa Bilim ve Teknoloji Dergisi, (Özel Sayı), 381-385.

\section{Öz}

Dünyada enerji kaynaklarının ve özellikle yenilenebilir enerji kaynaklarından jeotermal enerjinin yeri oldukça önemlidir. Jeotermal enerji, işletme maliyetinin ucuz olması, devreye girmesinin hızlı olması ve çevresel şartlardan etkilenmemesi gibi nedenlerden dolayı günümüzde elektrik enerjisi üretimi, 1sitma soğutma sistemleri, kimyasal madde ve mineral üretimi gibi birçok alanda oldukça tercih edilen bir yenilenebilir enerji kaynăğdır. Jeotermal enerjinin kullanılabilmesi için gerekli başlıca koşullar; ulaşılabilirlik, buharı ve sıcak suyu pazarlayabilmek amacıyla bir ürün haline getirmede dönüşüm teknolojisine sahip olmak ve ticari kullanımda ekonomik anlamda diğerleriyle rekabet edebilmek amacıyla etkin bir sürecin olmasıdır. Ülkemiz jeolojik ve coğrafik lokasyonu itibarıyla aktif bir tektonik kuşak üzerinde yer almaktadır. Bu yüzden jeotermal enerji açısından önemli bir potansiyele ve dünya ülkeleri arasında iyi bir konuma sahiptir. Günümüzde dünyada ve Türkiye'de nüfus artışı ve teknolojik gelişmelerin gittikçe artmasıyla birlikte, enerji tüketimi de buna bağlı olarak gün geçtikçe artmaktadır. Bu artışın ya da varsa trendin yıllara göre değişiminin belirlenmesi ve analiz edilmesi ilerisi için yapılacak planlamalarda büyük önem taşımaktadır. Bu çalışmada, Türkiye'nin 2009-2018 yılları arasındaki jeotermal enerji birincil enerji arzı istatistiksel analiz yöntemleri kullanılarak değerlendirilmiştir. Bunun için yıllara göre birincil enerji arzı verileri, istatistiksel analiz yöntemlerinden Mann-Kendall trend analizi ve Şen'in eğim testi ile analiz edilmiştir. Analiz sonuçları ve elde edilen grafikler incelendiğinde birincil enerji arzında pozitif yönlü bir trend olduğu ve özellikle 2013 yllı ve sonrasında bu trendde ciddi bir artış olduğu gözlemlenmiştir. Elde edilen tüm sonuçlar grafiklerle ve sonuç tablolarıyla detaylı olarak gösterilmiştir. Sonuç olarak nüfus artışı ve teknolojik ilerlemelere bağlı olarak jeotermal enerji birincil enerji arzının gittikçe artacağı düşünülmektedir.

Anahtar Kelimeler: Jeotermal enerji, Mann-Kendall trend analizi, Şen’in eğim testi.

\section{Evaluation of Geothermal Energy in Turkey in Terms of Primary Energy Supply}

\begin{abstract}
The place of energy resources and especially geothermal energy, which is one of the renewable energy sources, is very important in the world. Geothermal energy is a highly preferred renewable energy source in many areas such as electrical energy production, heating cooling systems, chemical material and mineral production due to reasons such as low operating costs, fast activation and not being affected by environmental conditions. The main conditions for the use of geothermal energy are accessibility, having the transformation technology into a product in order to market steam and hot water, and having an effective process in order to compete with others economically in commercial use. Our country is located on an active tectonic belt in terms of its geological and geographical location. Therefore, it has an important potential in terms of geothermal energy and a good position among the world countries. Today, with the growing of population growth and technological development in the world and in Turkey, energy consumption is increasing day by day depending on this. Determining and analyzing this increase or trend over the years has a great importance in future planning. In this study, the primary energy supply of geothermal energy in Turkey between $2009-2018$ were evaluated using statistical analysis methods. For this, primary energy supply data by years have been analyzed with statistical analysis methods Mann-Kendall trend analysis and Sen's slope test. When the analysis results and the graphs obtained are analyzed, it is observed that there is a positive trend in primary energy supply and a significant increase in this trend especially in 2013 and afterwards. All the obtained results are shown in detail with graphics and result tables. As a result, it is thought that the primary energy supply of geothermal energy will increase gradually due to population growth and technological advances.
\end{abstract}

Keywords: Geothermal energy, Mann-Kendall trend analysis, Sen's slope test. 


\section{Giriş}

Enerji kaynakları, bir ülkenin sosyal refahı ve ekonomik kalkınması için vazgeçilmez faktörlerden biridir (Kandemir, 2016). Günümüzde enerji kaynakları, fosil ve yenilenebilen enerji kaynakları olmak üzere iki kısımda açıklanmaktadır. Petrol, kömür ve doğal gaz gibi enerji kaynakları fosil enerji kaynakları olarak adlandırılmaktadır (Külekçi, 2009). Güneş, rüzgâr, biyokütle, hidrojen ve jeotermal enerji gibi enerji kaynakları ise yenilenebilir enerji kaynakları içerisinde incelenmektedir. Yenilenebilir enerji kaynakları çevre dostu, güvenilir ve sınırsız rezerve sahip olmaları nedeniyle fosil yakıtlara göre daha tercih edilebilir durumdadır (Çukurçayır ve Sağır, 2008; Zaim ve Çavşi, 2008).

Nüfus artışı ve teknolojik gelişmeler gün geçtikçe enerji tüketimini artırmaktadır (Açıkkalp ve Yerel Kandemir, 2018). Fosil enerji kaynaklarının yakın zamanda tükenecek olması, çevre problemlerine ve dışa bağımlılığa neden olmasından dolayı yenilenebilir enerji kaynakları kullanımı gün geçtikçe artmaktadır (Emeç vd. 2019). Jeotermal enerji kaynağı, yerkürenin ısısından kaynaklı sıcak bir akışkandan veya sıcak kuru kaya sistemlerinden elde edilen yenilenebilir bir enerji kaynağıdır (Mert ve Aydın, 2017). Jeotermal enerji yenilenebilir bir enerji kaynağı olması sebebiyle, işletme maliyeti diğer enerji türlerine göre daha ucuzdur ve devreye girmesi daha hızlıdır. Ayrıca çevresel şartlardan bağımsız olması onu tüm zamanlarda bakım hariç kullanılabilir kılmaktadır (Kayabaşı, 2018).

Ülkemiz çok önemli bir jeotermal kuşak üzerinde bulunmakta ve 1300’ün üzerinde jeotermal kaynak barındırmaktadır (Külekçi, 2009). Bundan dolayı, Türkiye jeotermal enerji kaynağı olarak Avrupa'da birinci dünyada ise yedinci sırada bulunmaktadır (Kayabaşı, 2018). Jeotermal kaynaklar su ve buhar sicaklıklarına göre sinıflandirılmaktadır. Su ve buharları $20-70^{\circ} \mathrm{C}$ arasında olan jeotermal kaynaklara düşük sicaklıklı jeotermal kaynaklar, $70-150^{\circ} \mathrm{C}$ olanlarına orta sicaklıklı jeotermal kaynaklar ve $150^{\circ} \mathrm{C}$ 'den fazla olanlarına ise yüksek sıcaklıklı (entalpili) jeotermal kaynaklar denilmektedir. Jeotermal kaynaklar günümüzde başta 1sıtma olmak üzere kimyasal madde üretiminden elektrik üretimine kadar birçok alanda kullanılmaktadır (Yozgat İl Özel İdare Müdürlüğü 2016; Kumbur vd. 2005; Kılıç ve Kılıç, 2013; Akın, 2016).

Bu çalışmada, Türkiye'nin 2009- 2018 yılları arasındaki jeotermal enerjideki birincil enerji arzı istatistiksel analiz tekniklerinden trend analizi kullanılarak incelenmiştir. Çalışmanın 2. bölümünde materyal ve metottan bahsedilecektir. 3. bölümde araştırma sonuçları ve tartışma kısmı yer almaktadır. 4. bölümde yer alan sonuç kısmında ise elde edilen tüm sonuçlar ve ileriye yönelik yapılabilecek çalışmalar detaylı olarak analiz edilmiştir.

\section{Materyal ve Metot}

\subsection{Veri Seti}

Bu çalışmada, Türkiye’nin 2009-2018 yılları arasındaki birincil enerji arzı bakımından trend analizi yapılmış ve kullanılan verilerin anlamlılı̆̆ incelenmiştir.

\subsection{Metot}

Son yıllarda enerji arzına etki eden parametrelerin analizinde parametrik olmayan testler yaygın olarak kullanılmaktadır. Paremetrik olmayan testlerde verilerin normal dağılmış olmasına gerek duyulmadan, verilerin sınıflama ya da sıralama ölçme düzeyinde toplanmış olması gerekmektedir. Örnekteki birim sayısı ne kadar artarsa parametrik olmayan testin gücü de o kadar artar. Bu nedenle çalışmamızda, Türkiyenin 2009-2018 yılları arasındaki birincil enerji arzındaki herhangi bir trend varlığı ve yönünün olup olmadığının belirlenmesi için parametrik testler yerine parametrik olmayan testlerden: Mann Kendall test ve Şen'in eğim testi kullanılmıştır.

\subsubsection{Mann Kendall Test}

Mann Kendall testi, bir zaman serisinin monoton yukarı trendinin mi yoksa monoton aşağı trendinin mi olduğunu belirler. Verilerin normal dağılmış olmasını veya doğrusal olmasını gerektirmez. Otokorelasyon olmamasını gerektirir. Mann-Kendall testinin istatistiği S, aşağıdaki (1) eşitlik kullanılarak hesaplanır. (Büyükyıldız ve Berktay, 2004)

$S=\sum_{i=1}^{n-1} \sum_{j=i+1}^{n} \operatorname{sgn}\left(x_{j}-x_{i}\right)$

$\operatorname{sgn}\left(x_{j}-x_{i}\right)=\left\{\begin{array}{cc}1 & \left(x_{j}-x_{i}\right)>0 \\ 0 & \left(x_{j}-x_{i}\right)=0 \\ -1 & \left(x_{j}-x_{i}\right)<0\end{array}\right.$

Verilerin varyans ise (3) numaralı eşitlik kullanılarak hesaplanır.

$\operatorname{Var}(S)=\frac{n(n-1)(2 n+5)-\sum_{t} t(t-1)(2 t+5)}{18}$ 
Varyansı belirlenen verilerin, Mann Kendall testine göre önemli olup olmadığı ise standart normal değişken olan z'nin eşitlik 4 ile hesaplanıp kritik z değeriyle karşılaştırılmasıyla belirlenmektedir. (Büyükyıldız ve Berktay, 2004)

$$
Z= \begin{cases}\frac{S-1}{\sqrt{\operatorname{Var}(S)}} & S>0 \\ 0 & S=0 \\ \frac{S+1}{\sqrt{\operatorname{Var}(S)}} & S<0\end{cases}
$$

Eğer seçilen $\alpha$ anlamlılık seviyesinde $|\mathrm{Z}| \leq \mathrm{Z}_{\alpha}$ ise $\mathrm{H}_{0}$ hipotezi kabul edilir, aksi halde reddedilir. Hesaplanan $\mathrm{S}$ değeri pozitif ise artan, negatif ise azalan bir trendin olduğu belirlenir.

\subsection{2. Şen'in eğim testi}

Eğer verilere ait zaman serisinde lineer bir trend mevcut ise gerçek eğim (birim zamandaki değişim) parametrik olmayan bir yöntem ile değerlendirilebilir. Bir dizi $(x, y)$ veri elemanına uyan bir regresyon çizgisinin eğimini tahmin etmenin en doğal yöntemi, en küçük kareler tahminine dayanır. Şen’in eğim testi veriler doğrusal bir çizgiye uymadığında geçerli değildir; aykırı değerlere karşı da hassastır. Şen'in eğimi şu şekilde tanımlanır (Gocic ve Trajkovic, 2013):

$x_{i}: i$ zamanındaki veriler ve $x_{j}: j$ zamanındaki veriler olmak üzere;

Şen'in eğimi: $Q_{k}=\left\{\frac{x_{j}-x_{i}}{j-i}: i<j\right\}$

$Q_{k}: k=(1, \ldots, N)$

$n$ zaman periyotlarının sayısı olmak üzere:

$N=n(n-1) / 2$

Hesaplanan $Q_{k}$ değerleri küçükten büyüğe doğru sıralanır. $N$ adet $Q_{k}$ değerinin medyanı alınarak ilgili gözlemin birim zamandaki değişimi aşağıdaki gibi hesaplanır:

$Q=Q_{(N+1) / 2} \quad \mathrm{~N}$ tek ise.

$Q=\frac{1}{2}\left[Q_{N / 2}+Q_{(N+2) / 2}\right] \mathrm{N}$ çift ise.

\section{Araştırma Sonuçları ve Tartışma}

Türkiye'nin enerji ihtiyacı giderek artmaktadır. Jeotermal enerji, işletme maliyetinin ucuz olması, devreye girmesinin hızlı olması ve çevresel şartlardan etkilenmemesi gibi birçok nedenden dolayı günümüzde tercih edilen bir yenilenebilir enerji kaynağıdır. Bu çalışmada, Türkiye'nin 2009-2018 yılları arasındaki jeotermal enerji birincil enerji arzı trend analizi kullanılarak incelenmiştir. Analizde kullanılan veriler Enerji Genel Müdürlüğü web sitesinden alınmıştır (https://www.eigm.gov.tr/tr-TR/). Alınan veriler analiz için derlenmiş ve betimleyici istatistik sonuçları Tablo 1'de verilmiştir.

Tablo 1 incelendiğinde gözlem sayısının 10 olduğu, ortalamanın 3400 ve varyansın 8982772 olduğu görülmektedir. Kullanılan verilere ait histogram grafiği ise Şekil 1'de verilmiştir. Şekil 2 'de jeotermal birincil enerji arzına ait saçılım grafiği, Şekil 3'de ise çizgi grafiği gösterilmektedir. Şekil 2 ve Şekil 3 incelendiğinde, verilerde artan bir trend olduğu görülmektedir. 2009 ile 2012 yılları arasında birincil enerji arzı değerlerinde çok az bir pozitif trend olmasına rağmen değerlerin birbirine oldukça yakın olduğu görülmektedir. Ancak özellikle 2013 yılı ve sonrasında jeotermal enerji birincil enerji arzında da ciddi bir artış ve pozitif yönde bir trend görülmektedir.

Tablo 1. 2009-2018 yılları arasındaki jeotermal enerji birincil enerji arzına ait betimleyici istatistik 


\begin{tabular}{ll}
\hline İstatistik & $\begin{array}{c}\text { Birincil Enerji } \\
\text { Arz1 } \\
\text { (JEOTERMAL)- } \\
\text { GWh }\end{array}$ \\
\hline Gözlem say1s1 & 10 \\
Minimum & 436 \\
Maksimum & 8343 \\
Medyan & 2493 \\
Ortalama & 3400 \\
Varyans & 8982772 \\
Standart sapma & 2997
\end{tabular}

Şekil 1. Jeotermal enerji birincil enerji arzina ait histogram

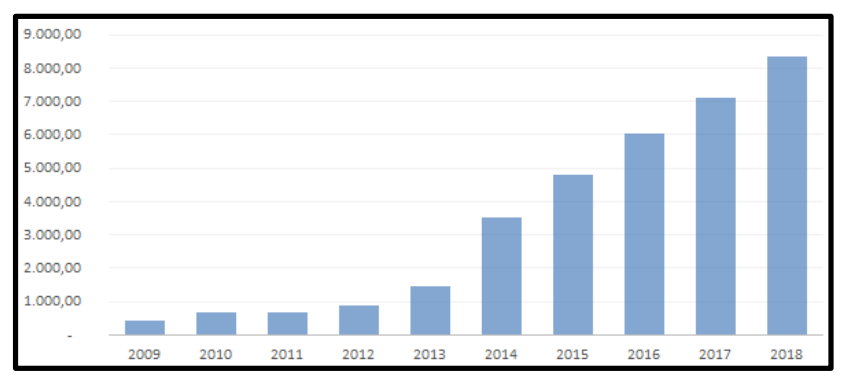

Şekil 2. Jeotermal enerji birincil enerji arzına ait saçılım grafiği

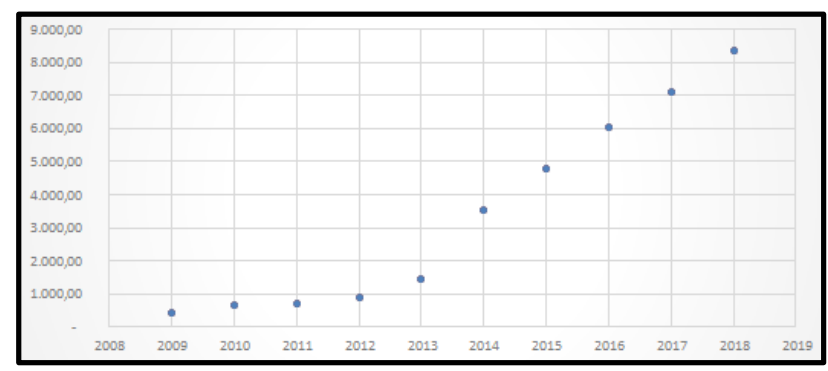

Şekil 3. Jeotermal enerji birincil enerji arzı verilerine ait çizgi grafiği

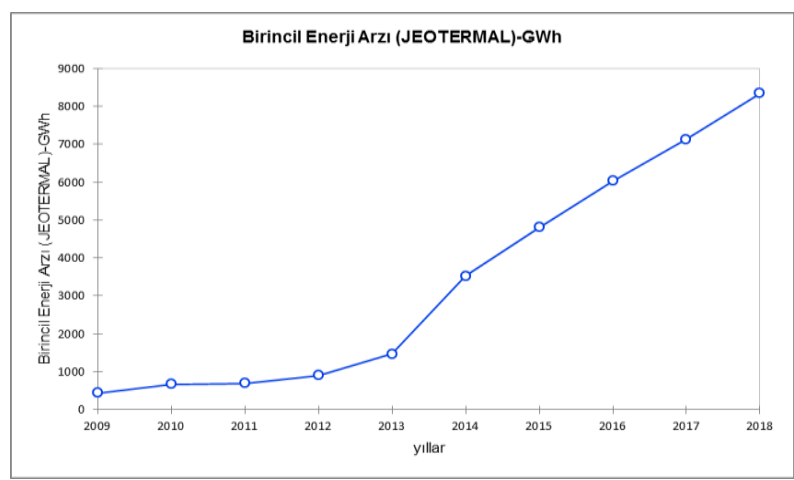

Türkiye'nin 2009-2018 yılları arasındaki jeotermal enerji birincil enerji arzı verilerine ait hipotez testleri aşağıda verilmiştir:

$H_{0}$ : Jeotermal enerji birincil enerji arzı verilerinde trend bulunmamaktadır.

$H_{a}$ : Jeotermal enerji birincil enerji arzı verilerinde trend bulunmaktadır.

Yukarıda verilen hipotez testleri Mann Kendall trend testi ile analiz edilmiş ve sonuçları Tablo 2'de verilmiştir. Tablo 2 incelendiğinde alfa 0,05 anlamlılık düzeyinde Kendall's tau değerinin $1, S$ değerinin $45, \operatorname{Var}(S)$ değerinin 125 olduğu görülmektedir. Hesaplanan $p$ değeri anlamllık düzeyi olan alfadan $(\alpha=0,05)$ küçük olduğundan, $H_{0}$ hipotezi reddedilir. $H_{a}$ kabul edilir. Yani jeotermal enerji birincil enerji arzı verilerinde trend bulunmaktadır. Elde edilen grafikler ile test sonucu uyumludur. 
European Journal of Science and Technology

Tablo 2. Mann-Kendall trend analizi sonuçları

\begin{tabular}{lr}
\hline Kendall's tau & 1 \\
$\mathrm{~S}$ & 45 \\
Var (S) & 125 \\
p-değeri (Çift yönlü) & $<0,0001$ \\
alfa & 0,05 \\
\hline
\end{tabular}

Tablo 3. Şen'in eğim testi

\begin{tabular}{llll}
\hline & Değer & $\begin{array}{l}\text { Alt smir } \\
(95 \%)\end{array}$ & $\begin{array}{l}\text { Üst smir } \\
(95 \%)\end{array}$ \\
\hline Eğim & 1068,000 & 714,000 & 1229,000 \\
Kesişim & $-2147054,000$ & $-2309368,000$ & $-1790763,000$ \\
\hline
\end{tabular}

Şen'in eğim testine göre (Tablo 3), alt sınır (\%95) iken eğim değeri 714; üst sınır (\%95) iken eğim değeri 1229 olarak bulunmaktadır. Kesişim noktası ise -2147054 'dir.

\section{Sonuç}

Jeotermal enerji, ülkemizde özellikle son zamanlarda hızla yayılan enerji türleri arasında yer almaktadır. Gerek doğaya ve insana olan zararsızlığı, gerekse düşük maliyetli olması sebebi ile en çok tercih edilen yenilenebilir enerji kaynakları arasında yer almaktadır. Jeotermal enerji günümüzde elektrik üretimi ve termal uygulamaların gerektirdiği endüstriyel süreçlerde oldukça fazla kullanılmaktadır. Yıllar içerisinde hem dünyada hem de ülkemizde birincil enerji arzına yönelik trendler görülmektedir. Ülkemiz çok önemli bir jeotermal kuşak üzerinde bulunduğundan ve jeotermal kaynak bakımından zengin olduğundan bu çalışma kapsamında, Türkiye'nin 2009- 2018 yılları arasındaki jeotermal enerjideki birincil enerji arzı istatistiksel analiz tekniklerinden trend analizi teknikleri kullanılarak incelenmiştir. Bu teknikler, Mann Kendall testi ve Şen'in eğim testidir. Kullanılan yöntemlerde ve elde edilen grafiklerde analiz edilen verilerde pozitif yönlü bir trend olduğu gözlemlenmiştir.

İleriki çalışmalarda farklı ülkelerdeki jeotermal enerji birincil enerji arzı incelenebilir ve bu arzın nasıl değiştiği ya da benzeştiği irdelenebilir. Jeotermal enerjinin farklı ülkelerdeki durumu göz önüne alınarak çeşitli trend analizleri kullanılarak elde edilen sonuçlar kıyaslanabilir.

\section{Kaynakça}

Açıkkalp, E., Yerel Kandemir, S. (2018). Optimum insulation thickness of the piping system with combined economic and environmental method. Energy Sources, Part A: Recovery, Utilization, and Environmental Effects, 40(23), 2876-2885.

Akın, G. (2016). Yozgat İlinin Jeotermal Kaynakları ve Özellikleri. Cumhuriyet Üniversitesi Fen-Edebiyat Fakültesi Fen Bilimleri Dergisi, 37, 100-112.

Büyükyıldız, M., Berktay, A. (2004). Parametrik olmayan testler kullanılarak sakarya havazası yağışlarının trend analizi, Selçuk Üniversitesi Mühendislik Mimarlık Fakültesi Dergisi, 19(2), 23-38.

Çukurçayır, M. A., Sağır, H. (2008). Enerji Sorunu, Çevre ve Alternatif Enerji Kaynakları. Selçuk Üniversitesi Sosyal Bilimler Enstitüsü Dergisi, 20, 257-278.

Emeç, Ş., Adar, T., Akkaya, G., Delice, E. K. (2019). Efficiency Assessment of Hydroelectric Power Plant in Turkey by Data Envelopment Analysis (DEA). Avrupa Bilim ve Teknoloji Dergisi, 34-45.

Gocic, M., Trajkovic, S. (2013). Analysis of changes in meteorological cariables using Mann-Kendall and Sen's slope estimator statistical test in Serbia. Global and Planetary Change, 100, 172-182.

Kandemir, S. Y. (2016). Assessment of coal deposit using multivariate statistical analysis techniques. Energy Sources, Part A: Recovery, Utilization, and Environmental Effects, 38(7), 1002-1006.

Kayabaşı, R. (2018). Jeotermal Enerji Kaynaklı Atık Isının Seralarda Kullanılması ve Sera Yetiştiriciliğine Etkisi. Soma Meslek Yüksekokulu Teknik Bilimler Dergisi, 3(27), 24-38.

Kılıç, Ç., Kılıç, F., Keskin, M. (2013). Jeotermal enerji ve Türkiye. Mühendis ve Makine, 54 (639), 45-56.

Kumbur, H., Özer, Z., Özsoy, D. H., Avcı, D. E. (2005). Türkiye'de geleneksel ve yenilenebilir enerji kaynaklarının potansiyeli ve çevresel etkilerinin karşılaştırılması, III. Ulusal Yenilenebilir Enerji Kaynakları Sempozyumu, Mersin.

Külekçi, Ö. C. (2009). Yenilenebilir enerji kaynakları arasında jeotermal enerjinin yeri ve Türkiye açısından önemi. Ankara Üniversitesi Çevrebilimleri Dergisi, 1(2), 83-91.

Mert, B. A., Aydın, A. (2017). Çaldıran/VAN Jeotermal Enerji Kaynakları ve Kullanım Olanaklarının Araştırılması. Yüzüncü Yıl Üniversitesi Fen Bilimleri Enstitüsü Dergisi, 22(1), 12-20.

Yozgat İl Özel İdare Müdürlüğü (2016), Yozgat Jeotermal Kaynakları ve Jeotermal Kuyu Bilgileri, 1-40, Yozgat.

Zaim, A., Çavşi, H. (2018). Türkiye'deki jeotermal enerji santrallerinin durumu. Mühendis ve Makine, 59 (691), 45-58. 